\title{
GEL FILTRATION OF FIBRINOLYTIC COMPONENTS OF BLOOD PLASMA IN MAN AND RABBIT
}

\author{
AKIKAZU TAKADA, YUMIKO TAKADA and UTAKO OKAMOTO \\ Department of Physiology, School of Medicine, \\ Keio University, Tokyo, Japan
}

(Received for publication March 30, 1965)

\section{INTRODUCTION}

This paper deals with a comparative aspect of the fibrinolytic system in man and rabbit, particularly relating to the "proactivator-like component" in rabbit plasma whose behavior is similar to proactivator A of human plasma fractionated by gel filtration and apparently acts as proactivator in the presence of a small amount of human globulin. The entity of this component has been remained yet quite obscure, but for the convenience it is tentatively called "proactivator-like component."

As reported in the previous paper ${ }^{1}$ by the authors, two kinds of proactivators in human plasma, proactivator $A$ and proactivator $B$, were respectively demonstrated by gel filtration using Sephadex G-200. These proactivators are easily converted into plasminogen activator by reacting with a relatively small amount of streptokinase (SK).

As to rabbit plasma, it is well known that the fibrinolytic system does not respond to a small amount of $\mathrm{SK}^{2}$. This may imply that rabbit plasma practically contains no proactivator in a strict sense. However, great increase of the sensibility of rabbit plasma to SK with the addition of a very small amount of human plasma globulin is also known.

The mechanism of the increasing sensibility of rabbit plasma to SK in the presence of human globulin has been generally explained as follows. Proactivator in the human globulin was activated by SK, then activator thus produced converted plasminogen of rabbit plasma to an active plasmin, even though direct evidence supporting the above mentioned hypothesis has not been established.

In the present investigation, fractionation of rabbit plasma was conducted by gel filtration using Sephadex G-200. Then each fraction obtained was mixed with the solutions containing a very small amount of human plasma globulin and an adequate amount of SK. Then activator activity of each aliquot was assayed 
with fibrinolytic system. Results thus obtained were discussed comparing with those of human plasma, and the existence of a proactivator-like component in rabbit plasma was suggested.

\section{MATERIALS AND METHODS}

Dried human plasma (Nihon Seiyaku Co. Ltd., Tokyo) was used.

Commercial preparations of fibrinogen (Fraction I, Armour Laboratory), thrombin (Mochida Co., Tokyo), plasminogen offered from AB Kabi, Stockholm and streptokinase (Varidase) from American Cyamid Co. were used in the following experiments.

\section{Euglobulin solution}

Plasma was diluted 20 fold with distilled water, and the reaction was adjusted to $\mathrm{pH} 5.2$ by addition of $0.1 \%$ acetic acid. The precipitate obtained by centrifugation for 10 minutes at $3,000 \mathrm{rpm}$ at $4^{\circ} \mathrm{C}$ was dissolved in phosphate saline buffer solution to provide an appropriate concentration suitable for experimental purposes.

\section{Urokinase solution}

Cellander's method $^{3)}$ was somewhat modified. Liquified urine foam was adjusted to $\mathrm{pH} 9.0$ by $1 \mathrm{~N}$ solution of $\mathrm{NaOH}$ and left at $4^{\circ} \mathrm{C}$ overnight. This.

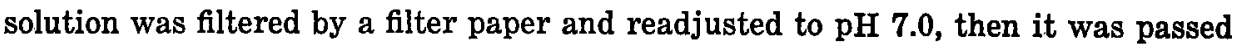
through silicic acid column $(2 \times 5 \mathrm{~cm})$. The same method with Ploug's ${ }^{4}$ was used in preparing silicic acid column and elution procedure. The effluent was placed on a fibrin plate and the fibrinolytic activity was tested. The large volume of the fibrinolytically active effluent was dialysed two times against water, and was concentrated to $1 / 15$ volume. This concentrated solution was redialysed against $0.1 \mathrm{M}$ sodium phosphate buffer solution (pH 6.5). This urokinase solution shows no lysis on a heated plate, and was used for the following experiments.

\section{Buffers}

$0.1 \mathrm{M}$ Tris- $\mathrm{HCl}$ ( $\mathrm{pH} \mathrm{8.0)}$ in $0.2 \mathrm{M} \mathrm{NaCl}$ was used as eluant in gel filtration; 1/15 M phosphate saline buffer ( $\mathrm{pH} 7.4$ ) and $0.18 \mathrm{M}$ borate saline buffer ( $\mathrm{pH}$ 7.75) were used for the test of streptokinase (SK) activated fibrinolysis and fibrin plate method, respectively. Thrombin dissolved in $0.9 \% \mathrm{NaCl}$ solution was used for clot formation.

\section{Gel filtration method}

This was almost the same as the method described in our previous paper"1). 
The column dimension was $2 \times 50 \mathrm{~cm}$ and the buffer used was Tris-HCl. Sephadex G-200 manufactured by AB Pharmacia, Uppsala was used.

Determination of fibrinolytic components of effluent

Proactivator

In the case of human plasma the activity was determined by the same method as described in the previous paper'1).

In the case of rabbit plasma the measurement was performed as follows. A $0.9 \mathrm{ml}$ of the effluent was mixed with $0.1 \mathrm{ml}$ of $\mathrm{SK}$ solution $(500 \mathrm{u} / \mathrm{ml})$ and $0.1 \mathrm{ml}$ of human euglobulin solution $(0.05 \mathrm{ml}$, when restored to plasma volume), then it was incubated at $37^{\circ} \mathrm{C}$ for 10 minutes. The lysing system was prepared by mixing $0.2 \mathrm{ml}$ of this activated solution with $0.3 \mathrm{ml}$ of $0.33 \%$ fibrinogen solution, $0.4 \mathrm{ml}$ of $1 / 15 \mathrm{M}$ phosphate saline buffer solution ( $\mathrm{pH} 7.4$ ) and $0.05 \mathrm{ml}$ of thrombin solution $(100 \mathrm{u} / \mathrm{ml})$. The time required for the complete lysis of the formed clot was measured in minutes at $37^{\circ} \mathrm{C}$. In the absence of human euglobulin in the reaction mixture, the clot could not show any lysis even when 0.1 $\mathrm{ml}$ of $5,000 \mathrm{u} / \mathrm{ml} \mathrm{SK}$ was contained.

\section{Inhibitor}

To determine the inhibitory action of the effluent, $0.1 \mathrm{ml}$ of plasminogen solution ( $0.1 \mathrm{mg}$ plasmonogen $/ \mathrm{ml}$ phosphate saline buffer) and $0.2 \mathrm{ml}$ of the effluent were mixed with $0.2 \mathrm{ml}$ of phosphate saline buffer, $0.1 \mathrm{ml}$ of SK (500u/ $\mathrm{ml}), 0.3 \mathrm{ml}$ of $0.33 \%$ fibrinogen solution and $0.05 \mathrm{ml}$ of thrombin solution (100 $\mathrm{u} / \mathrm{ml}$ ), then the reaction mixture was placed in water bath at $37^{\circ} \mathrm{C}$. The formed fibrin clot lysed at a definite time in the absence of inhibitory components in the effluent, but the lysis time became longer in the presence of inhibitory components.

\section{Plasminogen}

Plasminogen, activated with urokinase, was determined on heated plates. A $0.2 \mathrm{ml}$ of urokinase solution was added to $0.8 \mathrm{ml}$ of the effluent, and the mixture was incubated at $37^{\circ} \mathrm{C}$ for 10 minutes. The solution of $0.03 \mathrm{ml}$ was placed on heated plates ${ }^{5}$, and lysed areas were measured after incubation at $37^{\circ} \mathrm{C}$ for 18 hours.

\section{RESULTS AND DISCUSSION}

1. Existence of two kinds of proactivators in human plasma, proactivator A and proactivator $B$, was reported in the previous paper ${ }^{1}$. However, the separation of two peaks was not distinct enough. Therefore, the same experiment was 
repeated, but the longer column $(2 \times 50 \mathrm{~cm})$ was used. The rest of experimental details were the same as described in the previous paper ${ }^{11}$. Fig. 1 shows the filtration pattern of a solution dissolving $50 \mathrm{mg}$ of dried human plasma. Solid line in Fig. 1 indicates the curve representing reciprocal of lysis time. Results of fibrinolytic assay by heated plate indicates that proactivator A contains practically no plasminogen, while proactivator B contains some small amount of plasminogen. It is also noticed that proactivator A has larger molecular weight but proactivator $B$, small molecular weight.

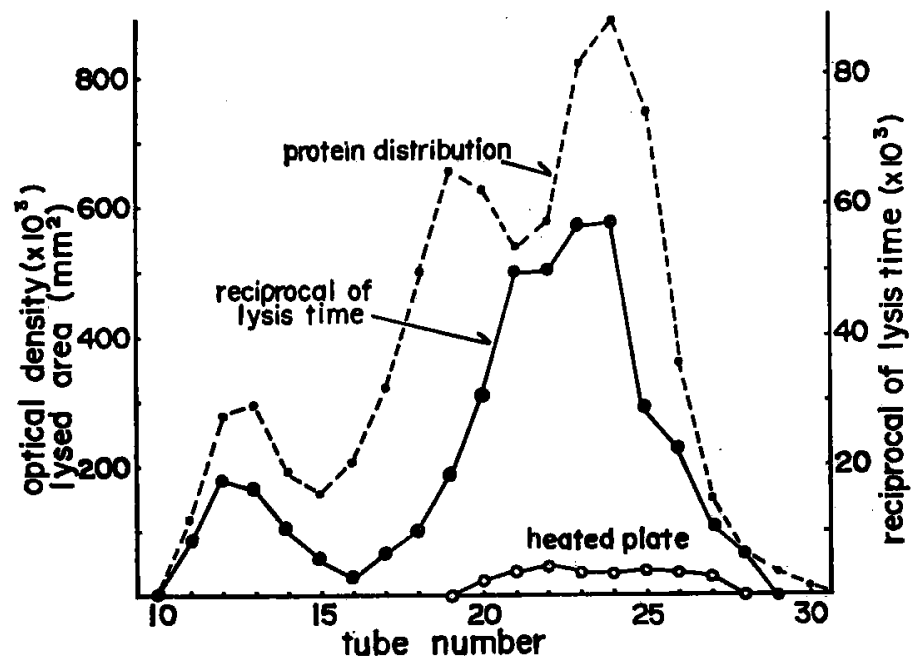

Fig. 1 Elution pattern of dried human plasma Column dimension: $2 \times 50 \mathrm{~cm}$ Eluant: $\quad 0.1 \mathrm{M}$ Tris- $\mathrm{HC1}, \mathrm{pH} 8.0$, each $5 \mathrm{ml}$ taken.

2. Fractionation of rabbit plasma was carried out by the same gel filtration system used in human plasma. Each fraction obtained showed no fibrinolytic activity when human euglobulin was not added. Fig. 2 shows the filtration pattern of $1 / 3 \mathrm{ml}$ of rabbit plasma. The solid line in the Figure indicates the curve representing reciprocal of the lysis time, which was measured by adding the reaction mixture containing SK and a small amount of human euglobulin. Distinct increase of activator activity is shown in serial fractions which correspond to those of proactivator $\mathrm{A}$ in human plasma and its peak was observed in around test tube number 12-13.

These results implied that rabbit plasma contains a component which behaved like proactivator $A$ of human plasma in gel filtration, and that this component acted like a proactivator $A$ in the presence of a small amount of human plasma. Another implication is that rabbit plasma contains a co-factor which 


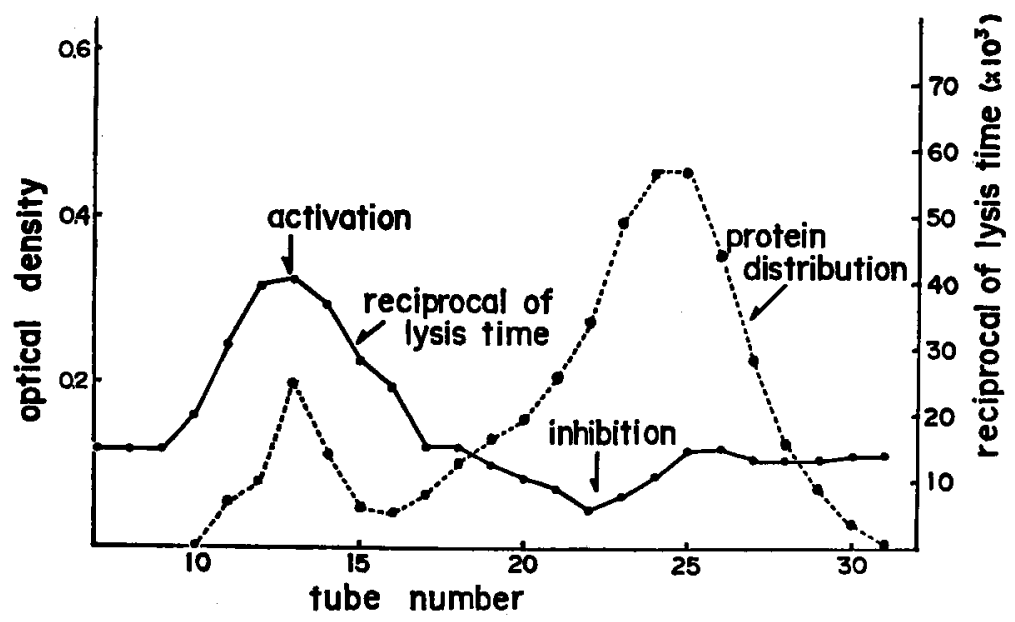

Fig. 2 Elution pattern of rabbit plasma

Column dimension: $2 \times 50 \mathrm{~cm}$

Eluant: $0.1 \mathrm{M}$ Tris-HC1, $\mathrm{pH} 8.0$, each $5 \mathrm{ml}$ taken.

accerelates the action of proactivator of human plasma. Further studies are under investigation by the authors.

3. The fractionation of rabbit plasma euglobulin was conducted by the same gel filtration system and the results obtained were shown in Fig. 3, indicating the presence of proactivator-like component in the euglobulin fraction of the rabbit plasma. Euglobulin corresponding to $7 \mathrm{ml}$ of rabbit plasma was added to the column.

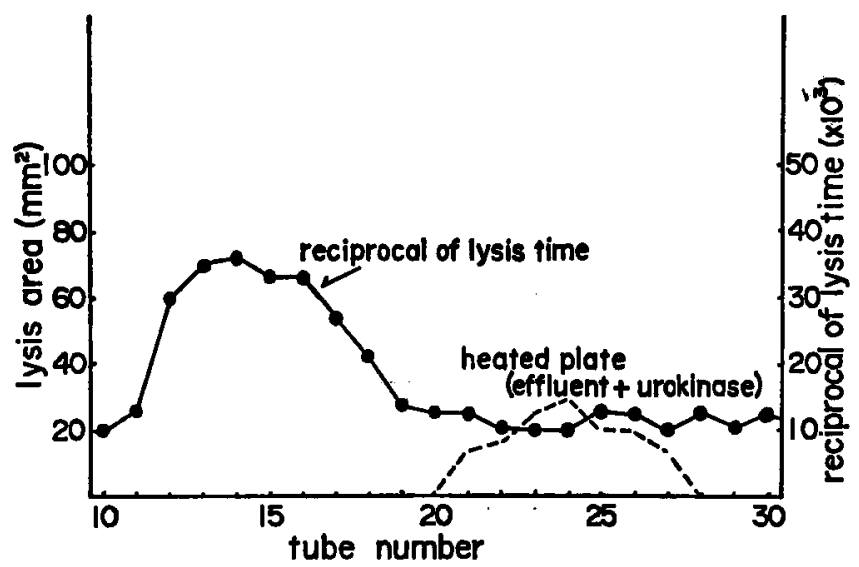

Fig. 3 Elution pattern of rabbit plasma euglobulin

Column dimension: $2 \times 50 \mathrm{~cm}$

Eluant: 0.1 M Tris-HC1, $\mathrm{pH} 8.0$, each $5 \mathrm{ml}$ taken. 
4. Beside the increased fibrinolytic activity in the fractions corresponding to proactivator A, some inhibition of the basic fibrinolysis (which induced by SK and added human euglobulin) was observed in those fractions corresponding to proactivator B of human plasma (Fig. 2, Fig. 4).

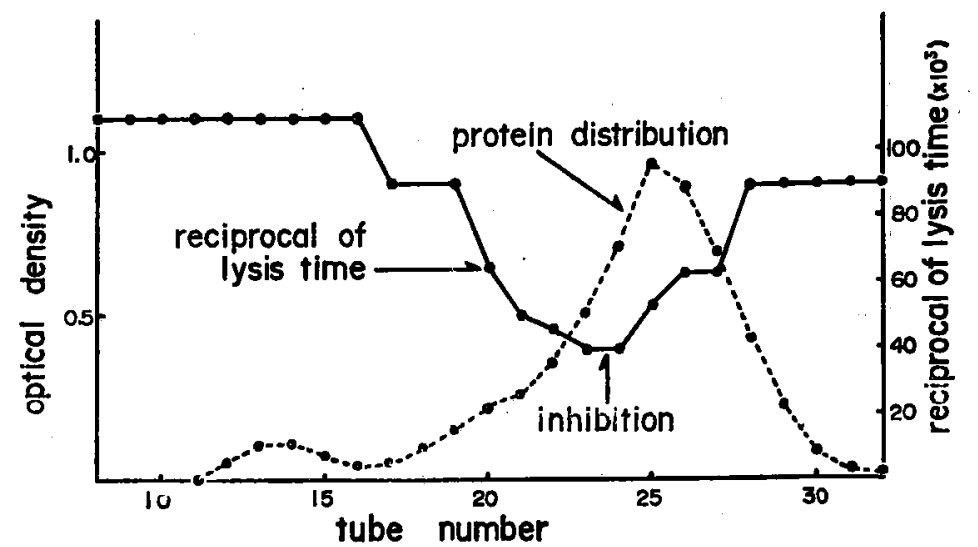

Fig. 4 Elution pattern of the supernatant $(5 \mathrm{ml})$ of rabbit plasma euglobulin

Column dimension: $2 \times 50 \mathrm{~cm}$

Eluant: $\quad 0.1 \mathrm{M}$ Tris-HC1, $\mathrm{pH} 8.0$, each $5 \mathrm{ml}$ taken.

Fractionation of plasma euglobulin of rabbits, however, showed no inhibition, as shown in Fig. 3. The remarkable inhibition was shown in the fractionation curve of the supernatant of rabbit plasma euglobulin fraction (Fig. 4). That is, some inhibitory component appeared in those fractions corresponding to proactivator $B$ of man; noteworthy is that proactivator $B$ belongs to euglobulin of man, while the inhibitory component does not.

Comparative aspect of the fibrinolytic system has been regarded as a clue of solving the complicity of the problem. Recently, the development of the fibrinolytic component has been studied ontogenetically by Ambrus et al ${ }^{(6)}$. Results presented here might be possibly the another characteristic aspect reflecting in a way the phylogenetical development of the system.

\section{CONCLUSION}

1) Results obtained by gel filtration of human plasma indicated the existence of two kinds of proactivators, $A$ and $B$, as reported in the previous paper').

2) Fractionation of rabbit plasma by the same gel filtration system indicated the existence of one active component whose behavior was similar to that of 
GEL FILTRATION OF FIBRINOLYTIC COMPONENTS OF BLOOD PLASMA 43

proactivator A of human plasma by filtration and showed an increased fibrinolytic activity with the presence of SK and small amount of human euglobulin. This active component belonged to euglobulin.

3) Any active component corresponding to proactivator $\mathbf{B}$ by filtration was not detected in rabbit plasma, but the existence of some inhibitory component to the basic fibrinolysis was observed in those fractions similar to proactivator $\mathrm{B}$ of human plasma.

The authors wish to express their hearty thanks to Prof. S. Okamoto, Kobe University, for his advice and kind discussions.

\section{REFERENCES}

1. Takada, A., Takada Y. and Okamoto, U.: Keio J. Med., 13: 187, 1964.

2. Müllertz, S. and Lassen, M.: Proc. Soc. Exp. Biol. Med., 82: 264, 1953.

3. Celander, D. R. and Guest, M. M.: Am. J. Card., 6: 409, 1960.

4. Ploug, J. and Kjeldgaard, N. O.: Arch. Biochem., 62: 500, 1956.

5. Lassen, M.: Acta Physiol. Scandinav., 27: 371, 1952.

6. Ambrus, C. M., Weintraub, D. H., Niswander, K. R. and Ambrus, J. L.: Pediatrics, $35: 91,1965$. 